تأثير بذور الكتان على بعض المعايير الفسلجية والكيموحيوية والنسجية في نسيج الكبد لطائر السمان

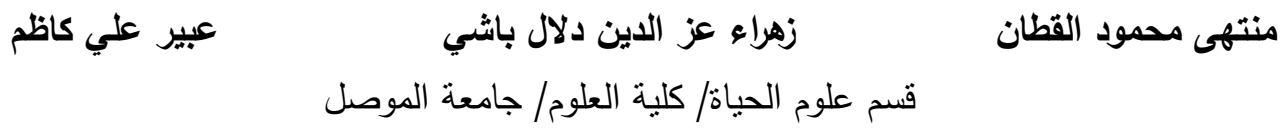

(أستلم 2013/11/12 ؛ُقلْ 2014/1/

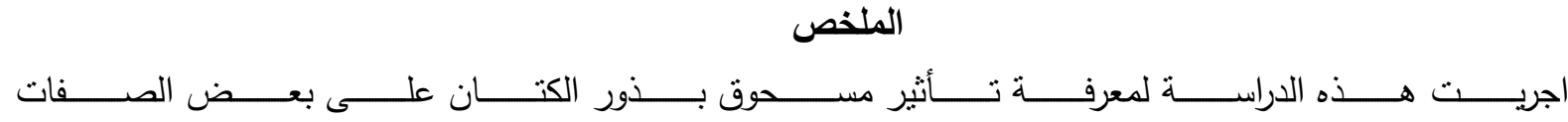

الكيموحيويـة والأنزيمـات الناقلـة للامسين ALST) Aspartateaminotransferase Alanineaminotransferease (ALT) Glutathione بالإضـافة إلى مستوى الكلوتاثيون مضـاد الاكسدة غير الأنزيمي وALP) Alkaline phosphatase ومستوى المالوندايالديهايد (GSH) مابين (175-200) غم واعمارها مابين (60-70) يوماً. قسمت الطيور الى خمس مجاميع بواقع 5 طيور /مجموعة، أعطيت بذور الكتان بعد طحنها ووضعها في كبسولات بتراكيز مختلفة وهي (250، 500، 1000، 2000) ملغم/كغم وزن جسم، وكانت معاملة الطيور يومياً ولمدة اربع اسابيع.

اوضحت النتائج ان مسحوق بذور الكتان قد حسن من الصفات الكيموحيويـة حيث ادى الى انخفاض معنوي في فعالية

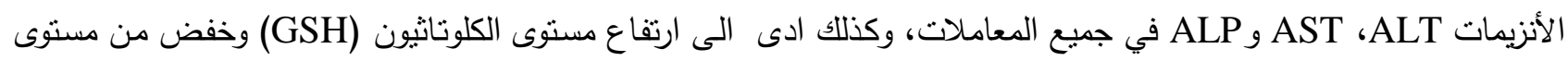

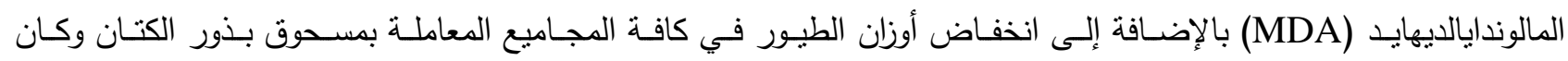
الانخفاض في وزن الطيور اشد في نركيز 2000 ملغم/كغم وزن جسم، كما بينت الفحوصات النسجية عدم وجود اختلافات نسجية لمجموعة الطيور المعاملة بـ 250 ملغم/كغم وزن جسم مقارنـة مع مجموعة السبطرة في حين أن باقي المعاملات اظهرت نأثيرات نسجية مرضية في نسيج الكبد.

الكلمات الدالة: مسحوق بذور الكتان، طائر السمان، الكلوتاثيون، المالوندايالديهايد، الكبد، صفات كيموحيوية.

\title{
The Effect of Flaxseeds on some Physiological and Biochemical Characters in Liver Tissue of Quail Birds
}

\author{
Muntaha M. Al-Kattan Zahra I. D. Bashi \\ Department of Biology/ College of Science/ University of Mosul
}

\begin{abstract}
This study was conducted to investigate the effect of flaxseed on some biochemical characteristics represented by ALT, AST ALP, enzymes, as well as to determine glutathione and malondialdehyde levels and body weight of birds which ranged between (175-200)g, (60-70) days old. Male Quail birds were divided into five groups 5 birds-group.

Flaxseeds were used after grinding in different concentrations as capsules of $(250,500,1000$, 2000) $\mathrm{mg} / \mathrm{kg}$ of body weight. The birds were treated daily with that flaxseeds powder.

Results showed a good improvement in the biochemical qualities as well as a rise in the level of glutathione and the reduction of MDA level in addition to lowering the body weights of birds, especially in the group given $2000 \mathrm{mg} / \mathrm{kg}$ of body weight.
\end{abstract}


Histological examinations showed no differences in comparison with the control group in birds given $250 \mathrm{mg} / \mathrm{kg}$ body weight of the flaxseeds while other groups showed pathological changes in liver tissue.

Keywords: Flaxseeds powder, Quail bird, glutathione, biochemical characteristics, malondialdehyde, liver.

\section{المقدمة}

إن من الوظائف الفسلجية المهمة للأطعمة والأعثاب الطبية هو الدور الوقائي للكائنات الحية من الأضرار التأكسدية ومنع

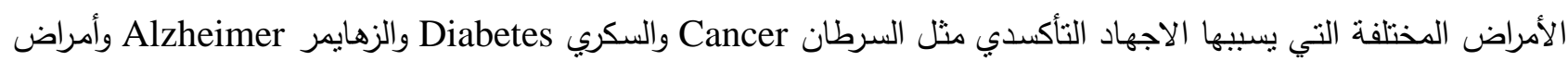
القلب الوعائية Cardiovascular وآفات التعصد Atheroseclerosis) (Devasagayam et al., 2004). ولقد جعل الله سبحانه وتعالى في العديد من النباتات او مستخلصاتها دورا في معالجة الأمراض المختلفة ومن ضمنها مضادات للأكسدة مع المواد الحيوية في الجسم للوقاية من الاجهاد التأكسدي Oxidative Stress الناتج من تفاعلات الجذور الحرة Free radicals.

واثتتت الابحاث العلمية الحديثة الفاعلية الدوائية لكثير من النباتات التي استعملتها الثـوب المختلفة منذ القدم لعلاج العديد من الحالات المرضية منها:

أمراض البرد، السعال، المغص، وطرد الغازات، كما استخدمت لعلاج الجروح والتقرحات، والاسهال وكمواد مضادة للحمى التى

والتهابات الجهاز التتفسي وأمراض الكبد والسرطانات وأمراض القلب والسكري (Chaudhary et al., 2010). يشكل الضرر التأكسدي Oxidative damage للخلايا والانسجة دوراً مهماً في نشوء الأمراض المختلفة عند الانسان بسبب الاضرار الكبيرة في المكونات الحيويـة (اللبيدات، البروتينات، الكربوهيدرات، الاحماض النوويـة) مسببة بيروكسيدة الدهن

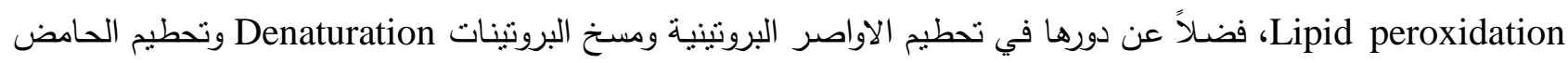
النووي Mutations الذي يؤدي الى حدوث الطفرات DNA التقود الى حدوث الاورام السرطانية (Tsao et al., 2004). وهناك بعض النباتات التي تقلل من خطر هذه الجذور مما يقلل من خطر الاصابة بالكثير من الأمراض وقد يستخدم النبات ككل او جزء منه كالاوراق والبذور والثمار والسيقان ومن هذه النباتات التي تستخدم بذورها هو نبات الكتان الذي استخدمنا بذوره في هذه التهات

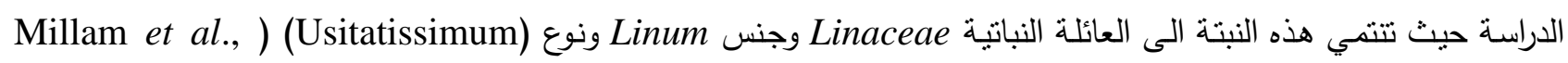

والكتان نبات حولي او ثنائي الحول او معمر يصل ارتفاعه الى حوالي متر ، لـ ساق نحيلة واوراق رمحية وازهار زرقاء،



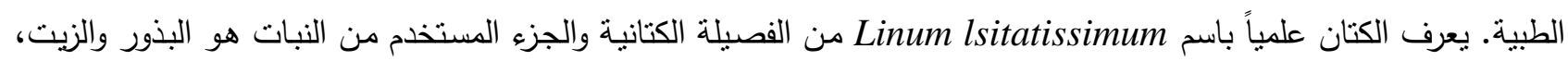
الموطن الاصلي لنبات الكتان هو المناطق المعتدلة من أوربا وآسيا، ويزرع حالياً في جميع انحاء العالم من اجل اليافه وبذوره وزيته (Millam et al., 2005).

تحتوي بذور الكتان على Linolenic acid بكميات وافرة وهو أحد الاحماض الدهنيـة غير المشبعة الموجودة في Omega3 وهو يشبه تلك الموجودة في الاسماك الدهنية Fatty fish، ويحتوي على الفينولات المتعددة وهي من أقوى مضادات الأكسدة بالاضافة الى محتوى عالي من البوتاسيوم والمغنيسيوم والألياف ومجموعة فيتامينات B والزناتك وكذللك تحتوي على اللكنين



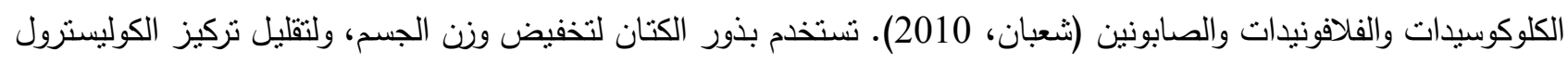
الضـار LDL-c ورفع الكوليسترول الحميد HDL-c، وتقليل نركيز الكليسيريدات الثلاثيـة وكذللك تمنع تكوين الخثرات الدمويـة 
Omega3 Fatty acid وتحسين وظائف الكبد، وخفض مستوى السكر بسبب احتوائها على مستوى عالي من الالياف وكذللك

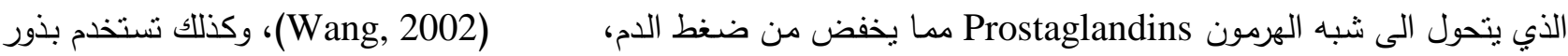
الكتان لعلاج الإمساك، والقرح المعدية ويزيد من امتصاص الكاليسيوم (Morris, 2007). الهذف من الاراسة

استهدفت هذه الدراسة اختبار فعالية بذور الكتان بالتراكيز المختلفة كمضاد للاكسدة من خلال قياس مستوى الكلوتاثيون مضاد الاكسدة غير الأنزيمي في نسيج الكبد مستوى المالوندايالديهايد. ودراسة نأثير بذور الكتان بالتراكيز المختلفة على فعالية أنزيمات الكبد منل أنزيم ناقل الامين الألنين ALT والناقل الامين للاسبارتيت AST وكذلك أنزيم الفوسفاتيز القاعدي ALP. ودراسـة تأثير التراكيز المختلفة لبذور الكتان على انسجة الكبد وكذلك استهدفت الدراسـة تأثنير بذور الكتان بـالتراكيز المختلفة على اوزان طائر السمان.

\section{المواد وطرائق العمل}

بذور الكتان

استخدم في هذه الدراسة بذور الكتان التي تم الحصول عليها من الاسواق المحلية وبعد التأكد من تصنيفها اعنماداً على

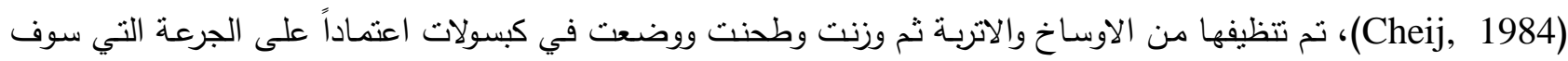
تعطى للطيور وحسب اوزان الطيور • الحيوانات المستخدمة استخدم في هذه الدراسة 25 ذكراً من طيور السمان Quail Coturinx coturinx (الكتاني، 1980)، تراوحت اعمارها مابين (60-70) يوماً وبأوزان تراوحت ما بين (175-200) غم، وبعد شرائها من الاسواق المحلية وضعت في اقفاص مصنوعة من الالمنيوم معدة لهذا الغرض وتحت ظروف ملائكة من حرارة نراوحت ما بين (25-28) مْ وإضاءة حوالي 15 ساعة ضوه 9

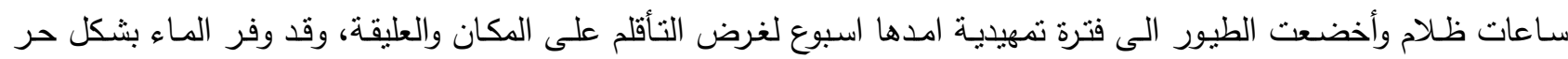
للطيور حيث قدم الماء بواسطة مناهل خاصة بالطيور • العليقة المستخدمة في الدراسة تمت تغذية الطيور على عليقة خاصة بتغذية طائر السمان، إذ تم تجهيزها واعدادها من شركة الأمين للدواجن المحدودة في الموصل وقد جرى تقديم العلف بشكل ثابت وبمواعيد ثابتة لكل المجاميع، وكانت التغذية حرة، وكذلك الماء طبلة فترة المعاملة.


قسمت الطيور الى خمسة مجاميع ثم تم ايجاد معدل الاوزان الاولية لكل مجموعة ومعدل الوزن بعد اربع اسابيع من بدء المعاملة (يوم الذبح في نهاية المعاملة). - تصميم التجرية والمعاملة بعد انتهاء الفترة التمهيدية التي أمدها أسبوع بدأت المعاملة حيث قسمث الطيور الى خمس مجاميع وكان التقسيم عشوائياً وبواقع خمسة طيور /مجموعة. 1- المجموعة الاولى السبطرة: تضمنت خمسة طيور معدل الوزن الاولي (159.8) غم اعطيت طيور هذه المجموعة عليقة قياسية وماء اعتيادي وجرعت كبسولات فارغة لمعادلة اجهاد مسك الطيور (Batchelor and Giddins, 1995). 2- المجموعة الثانية: تضمنت خمسة طيور معدل الوزن الاولي (164.2) غم اعطيت طيور هذه المجموعة مسحوق بذور الكتان بواقع 250 ملغم/كغم وزن جسم مع عليقة قياسية وماء اعتيادي. 
3- المجموعة الثالثة: تضمنت خمسـة طيور معدل الوزن الاولي (156.2) غم، اعطيت طيور هذه المجموعة مسحوق بذور الكتان بواقع 500 ملغم/كغم وزن جسم مع عليقة قياسية وماء اعتيادي.

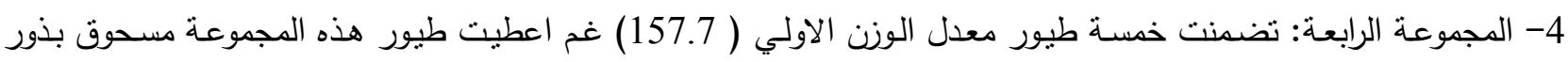
الكتان بواقع 1000 ملغم/كغم وزن جسم مع عليقة قياسية وماء اعنيادي.

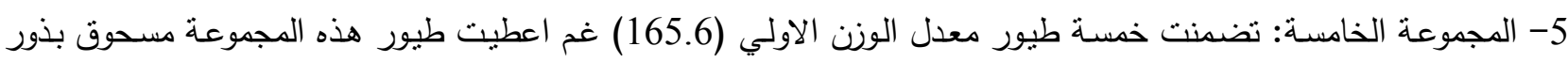
الكتان بواقع 2000 ملغم/كغم وزن جسم مع عليقة قياسية وماء اعتيادي.

تحضير مستخلص النسيج (الاراسة النسجية) بعد انتهاء فترة المعاملة تم ذبح جميع الطيور وتم أخذ الاكباد لإجراء الفحوصات الكيموحيوية والنسجية حيث تم تقسيمه إلى جزئين الجزء الاول وضع في - 80مْ لحين إجراء الفحوصات الكيموحيوية والجزء الثناني تم تقطيعه إلى قطع صغيرة ووضع

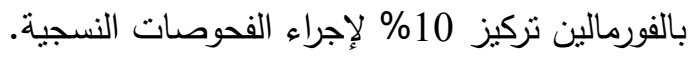

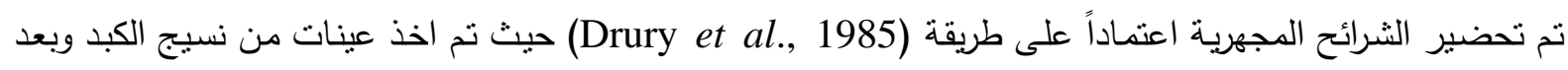

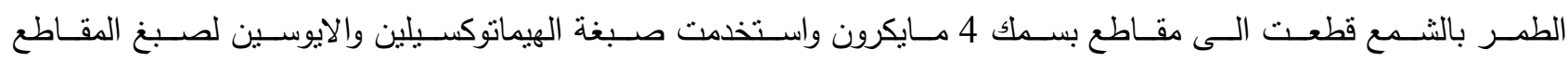
(Luna, 1968)، بعد ذلك اجري الفحص المجهري للمقاطع النسجية باستخدام المجهر الضوئي المركب، كما صورت المقاطع النسجية المنتخبة باستخدام المجرر الخاص Line altay biolab المزود بآلة تصوير خاصة عائدة إلى كلية الطب البيطري.

1- تقدير فعالية أنزيم ناقل الأمين الألنين (ALT) Alanine amino transferees

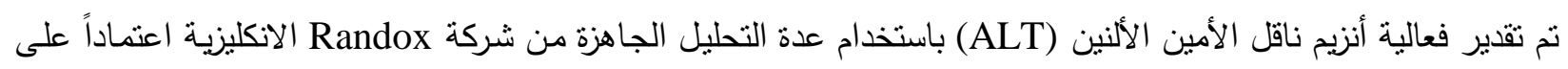

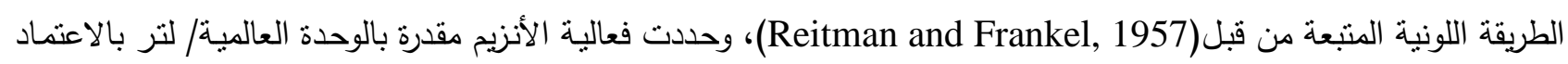

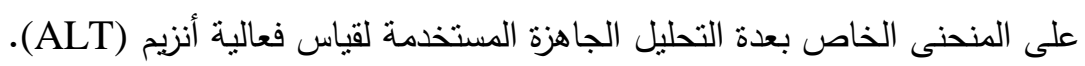
2- تقدير فعالية ناقل الأمين الاسبارتيت (AST)Aspartate amino transferees

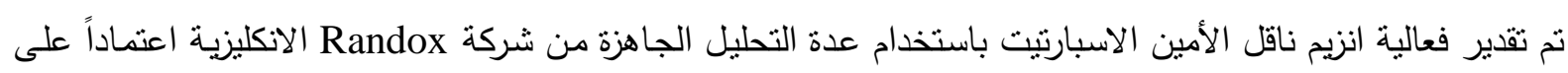
الطريقة اللونية المنبعة من فبل (Reitman and Frankel, 1957)، اذ يعمل أنزيم (AST) الموجود في الراشح على تحويل

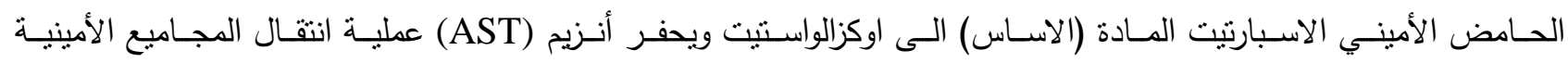
Transamination

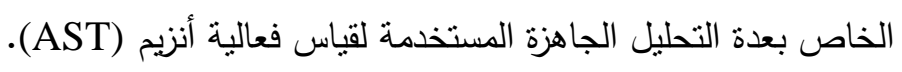
(ALP) Alkaline phosphatase 3 قدرت فعالية أنزيم الفوسفاتيز القاعدي باستخدام عدة التحليل الجاهزة والمصنعة من قبل Biolabo-France بالاعتماد على الطريقة التي اتبعها (Kind and King, 1954) التي تعتمد على تحليل فوسفات الفينول Phenyl phosphate وتحويلها الى الفوسفات والفينول في وسط قاعدي بتحفيز أنزيم الفوسفاتيز القاعدي وكما موضح في إندها المعادلة. ALP

Phenyl phosphate Phosphat + phenol $\mathrm{pH}=10$ 


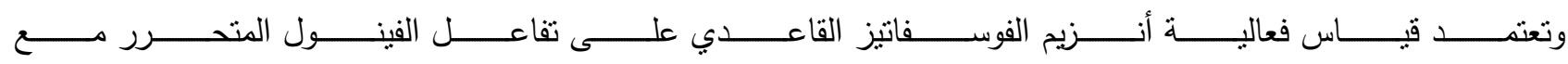
1,4- amino antipyrine اللون الوردي المائل إلى الاحمرار والذي يمكن قياس شدة امتصاصيته عند الطول الموجي 510 نانوميتر . تقدير تركيز بيروكسيدة الدهن في نسيج الكبد الدمري استخدمت الطريقة المتبعة من قبل الباحث (Gilbert et al., 1984) لتقدير تركيز بيروكسيدة الدهن في نسيج الكبد وذلك


على التفاعل بين بيروكسيدات الدهن بشكل رئيسي المالوندايالديهايد وبين حامض ثايوبارباتيورك ويعتمد هذا التفاعل على الدالة

الحامضية.

تقدير تركيز الكلوتاثيون في نسيج الكبد

تم تقدير نركيز الكلوتاثيون في نسيج الكبد بالاعتماد على (Moron et al., 1979).

التحليل الاحصائي

حلت النتائج احصائباً وفق نظام التجارب العاملية البسبطة بالتصميم العشوائي الكامل، واستخدم اختبار دنكن المتعدد المدى لاختبار الفروقات بين المجاميع وكانت النتائج معنوية عند مستوى احتمال (SAS SAS واختبار Covariance لاستخراج LSD (عنتر ، 2010).

\section{النتائج و المناقشة}

يوضح الجدول (1) حدوث انخفاض معنوي (0.05 > p) في فعالية أنزيم ناقل امين الألنين (ALT) لنسيج كبد ذكور

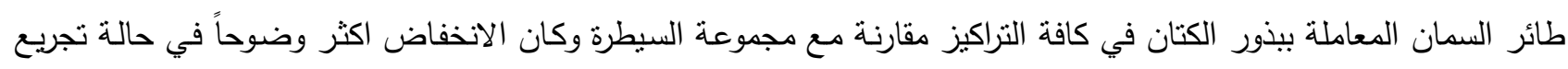

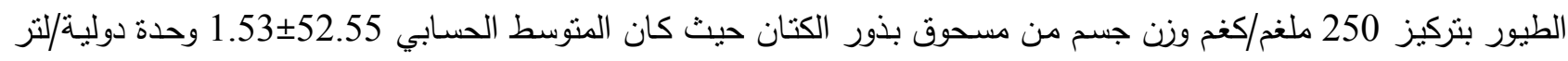

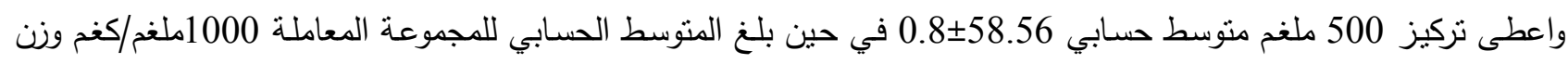
جسم 70.27 7.17 وحدة دولية/لتزر واخيراً اعطى تركيز 2000 ملغم/كغم وزن جسم من مسحوق بذور الكتان متوسط حسابي

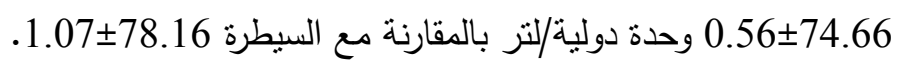
ويوضح الجدول (1) حدوث انخفاض معنوي (14) (1) 0.05 في فعالية أنزيم ناقل الأمين AST الاسبارتيت امينو ترانس

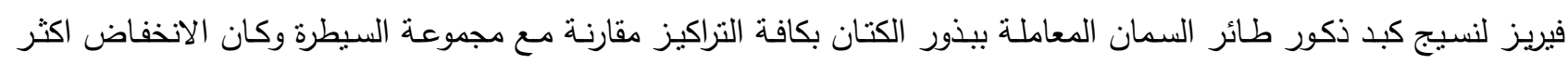
وضوحاً في حالة تجريع الطيور مسحوق بذور الكتان بنركيز 250ملغم/كغم وزن جسم، اذ كانت الفعالية 14.72 دوليـة/لتر واعطى تركيز 500 ملغم/كغم وزن جسم 16.26 0.38 وحدة دولية/لتز واعطى تركيز 1000 ملغم/كغم وزن جسم


السيطرة $0.26 \pm 25.18$ وحدة دولية/لتر.

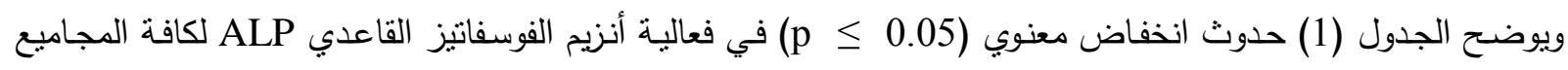
المعاملة ببذور الكتان مقارنة مع مجموعة السيطرة وكان الانخفاض اكثر وضوحاً في مجموعة الطيور المعطاة بذور الكتان بتركيز

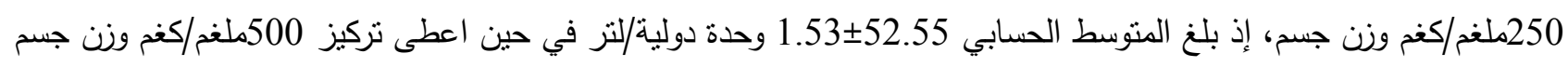

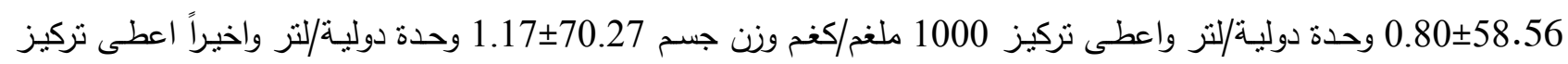

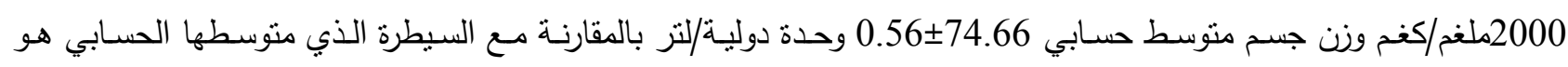
1.07士78.16 
الجدول 1: تأثير تراكيز مختلفة من مسحوق بذور الكتان على فعالية الانزيمات ALT، وAST، وALP في النسيج الكبدي لأكور طائر السمان. ان.

\begin{tabular}{|c|c|c|c|c|c|}
\hline بذانور الكتان & بذور الكتان & بذور الكتان & بذور 250ملفم/كفم & مجيوعة السيطرة عليقة & וג山 \\
\hline $\begin{array}{c}0.56 \pm 74.66 \\
b\end{array}$ & $\begin{array}{c}1.17 \pm 70.27 \\
\mathrm{c}\end{array}$ & $\begin{array}{c}0.80 \pm 58.56 \\
\mathrm{~d}\end{array}$ & $\begin{array}{c}1.53 \pm 52.55 \\
\mathrm{e}\end{array}$ & $\begin{array}{c}1.07 \pm 78.1 \\
6 \mathrm{a}\end{array}$ & وحدة دولية/لتز \\
\hline $\begin{array}{c}1.02 \pm 20.96 \\
b\end{array}$ & $\begin{array}{c}0.25 \pm 17.10 \\
\mathrm{c}\end{array}$ & $\begin{array}{c}0.38 \pm 16.26 \\
\mathrm{~d}\end{array}$ & $\begin{array}{c}0.48 \pm 14.72 \\
\mathrm{e}\end{array}$ & $\begin{array}{c}0.26 \pm 25.1 \\
8 \mathrm{a}\end{array}$ & وحدة دولية/لتز \\
\hline $\begin{array}{c}0.56 \pm 74.66 \\
b\end{array}$ & $\begin{array}{c}1.17 \pm 70.27 \\
\mathrm{c}\end{array}$ & $\begin{array}{c}0.80 \pm 58.56 \\
\mathrm{~d}\end{array}$ & $\begin{array}{c}1.53 \pm 52.55 \\
\mathrm{e}\end{array}$ & $\begin{array}{c}1.07 \pm 78.1 \\
6 \mathrm{a}\end{array}$ & وحدة ALP \\
\hline
\end{tabular}

- القيم معبر عنها بالمتوسط الحسابي 土 الانحراف القياسي وعدد الطيور / مجموعة=5

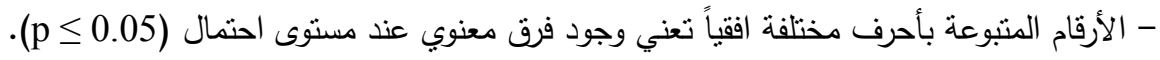

إن الانخفاض الحاصل في فعالية الأنزيمات الناقلة للامين ALT, AST نتيجة للمعاملة ببذور الكتان قد يعزى لاحتواء بذور الكتان على Omega3 fatty acid الذي يتحول إلى شبه الهرمون Prostaglandins والذي له دور كبير في كسح الجذور الحرة، كذللك احتواء بذور الكتان على الفينولات المتعددة Polyphenols والكلايكوسيدات Glycosides وفيتامين A,E وجميعها مضادات اكسدة قوية تساهم في حماية خلايا الكبد من التلف نتيجة الاجهاد الناتجة من تفاعلات الجذور الحرة ومن ثم تحسين

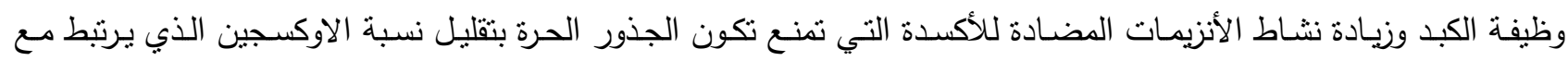

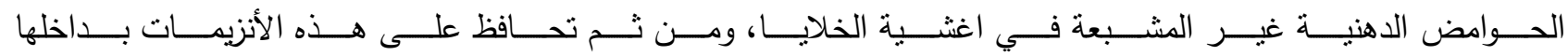
وتمنع انتقالها إلى الدم والحفاظ على المستوى الطبيعي للأنزيمات الكبدية في مصل الدم (Sreelatha and Inbavalli, 2012). أما قدرة بذور الكتان على تثبيط فعالية أنزيم ALP قد يعود لإحتواء بذور الكتان على مجموعة فيتامينات B-complex ومنها

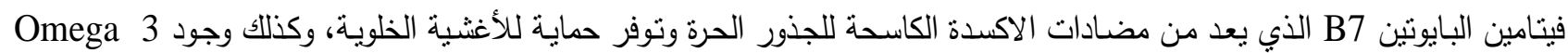
.(Morris, 2007)

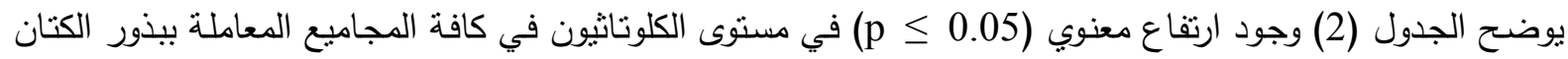
مقارنة مع مجموعة السيطرة وكان الارتفاع اكثر وضوحاً في المجموعة المعاملة ببذور الكتان بتركيز 250 ملغم/كغم وزن جسم إذ إدي

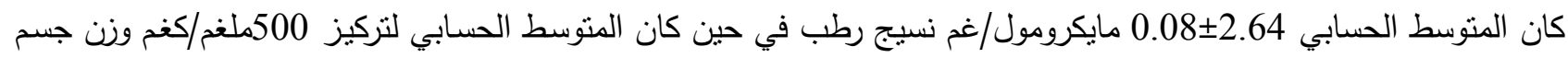
2.12 0.12 مايكرومول/غم نسيج رطب وتركيز 1000ملغم/كغم وزن جسم 2.06 0.05 مايكرومول/غم نسيج رطب، واخيراً

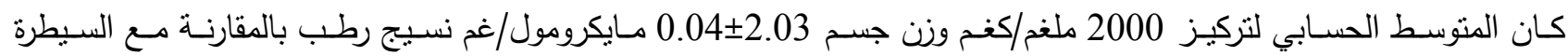

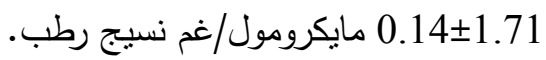
ويوضح الجدول (2) وجود انخفاض معنوي (0.05 > p ) في مستوى المالوندايالديهايد في كافة المجاميع المعاملة ببذور


جسم ايضا حيث كان المتوسط الحسابي 369.98_94.04 مايكرومول/غم نسيج رطب اما تركيز 500 ملغم/كغم وزن جسم فكان

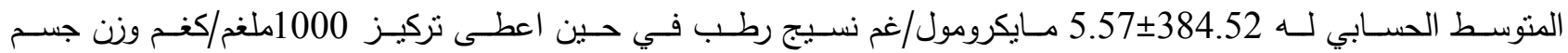




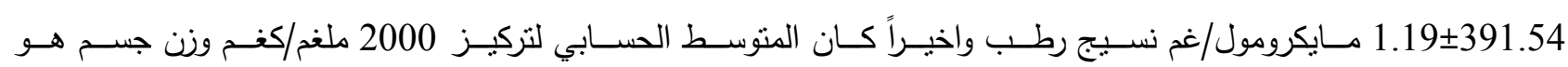



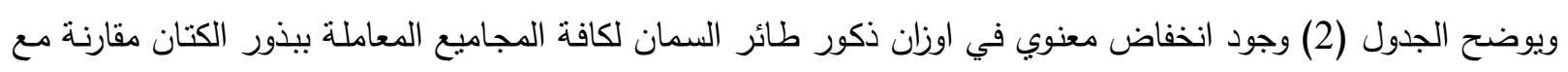

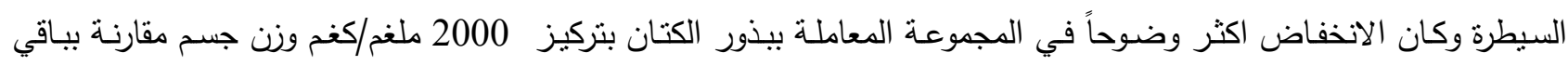

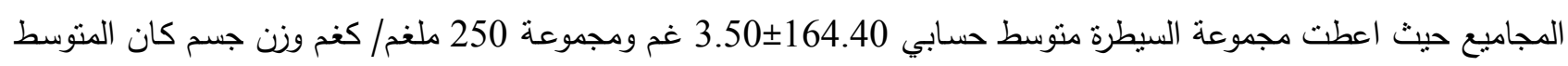

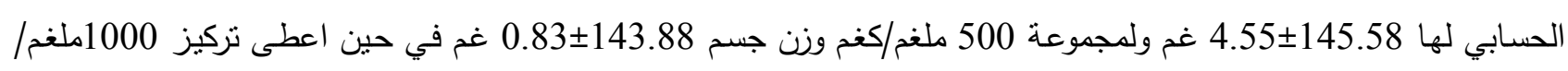
كغم وزن جسم 140.90_0.83 غم واخيراً اعطى نركيز 2000 ملغم/كغم وزن جسم

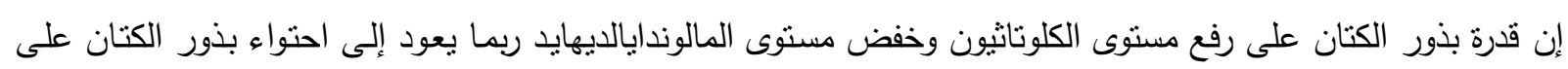
فيتامين A وفيتامين E التي تعتبر من اقوى مضادات الاكسدة الكاسحة للجذور الحرة (Mukherjee, 2003) وكذلك احتوائها


الذي يعمل كمضاد اكسدة يوفر الحماية لاغشية الخلايا من تفاعلات الجذور الحرة مما يؤدي إلى رفع مستوى الكلوتاثيون وخفض الإنى مستوى المالوندايالديهايد، وتحتوي بذور الكتان على مستوى عالي من الفايتواستروجين Phytoestrogen وهي إستروجينات نباتية

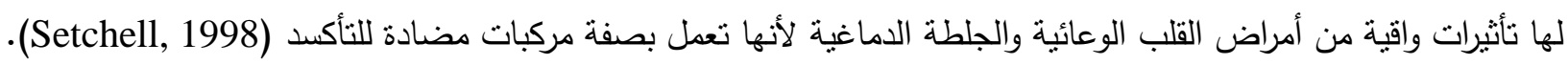

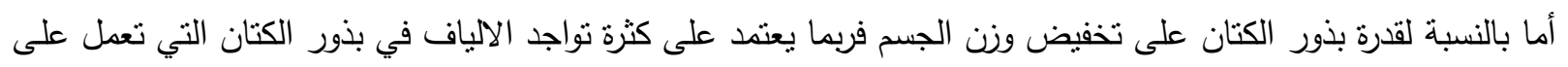

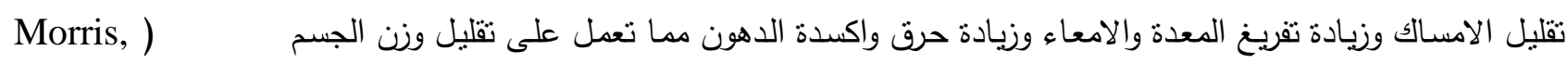
.$(2007$

الجدول 2: تأثير تراكيز مختلفـة مـن مسـحوق بذور الكتان على مستوى الكلوتـاثيون المالوندايالديهايـا واوزان ذكور طائر السمان

\begin{tabular}{|c|c|c|c|c|c|}
\hline بذور الكتان & بذانور الكتان & بذور الكتان & وزن 250ملفم/كفم الكتان & قالسيطرة عليقة & \\
\hline $\begin{array}{c}0.04 \pm 2.03 \\
b\end{array}$ & $\begin{array}{c}0.05 \pm 2.06 \\
b\end{array}$ & $\begin{array}{c}0.12 \pm 2.15 \\
b\end{array}$ & $\begin{array}{c}0.08 \pm 2.64 \\
\mathrm{a}\end{array}$ & $\begin{array}{c}0.14 \pm 1.71 \\
\mathrm{c}\end{array}$ &  \\
\hline $\begin{array}{c}1.63 \pm 395.90 \\
b\end{array}$ & $\begin{array}{c}1.19 \pm 391.54 \\
b\end{array}$ & $\begin{array}{c}5.57 \pm 384.52 \\
b\end{array}$ & $\begin{array}{c}9.04 \pm 369.98 \\
\mathrm{c}\end{array}$ & $\begin{array}{c}14.88 \pm 408.5 \\
8 \\
a\end{array}$ & 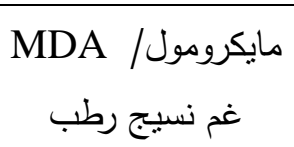 \\
\hline $\begin{array}{c}0.90 \pm 125.94 \\
b\end{array}$ & $\begin{array}{c}0.83 \pm 140.90 \\
\mathrm{c}\end{array}$ & $\begin{array}{c}0.83 \pm 143.88 \\
\mathrm{c}\end{array}$ & $\begin{array}{c}4.55 \pm 145.58 \\
\mathrm{~b}\end{array}$ & $\begin{array}{c}3.50 \pm 164.40 \\
\mathrm{a} \\
\end{array}$ & وزن الجسم بالغرام \\
\hline
\end{tabular}




أظهرت المقاطع النسجية عدم حدوث تغيرات في نسيج الكبد عند استخدام نركيز 250 ملغم/كغم وزن جسم حيث التركيب السوي والثكل المنتظم للوريد المركزي وهو مشـابه لمجموعة السيطرة في حين ادت التراكيز العالية من مسحوق بذور الكتان الى لى حدوث تغيرات سلبية على نسيج الكبد متمتلة بظهور تجمعات دهنية وتفجي الخلايـا في المقطع النسجي للكبد في تركيز 500 ملغم/كغم وزن جسم امـا في تركيز 1000 ملغم/كغم وزن جسم من بذور الكتان فقد حدث نوسع للوريد المركزي مـع عدم انتظام شكله وارتتاح بؤري للخلايا احادية النواة بالقرب من الوريد المركزي، وعند المعاملة بتركيز 2000 ملغم/كغم وزن جسم من بذور الكتان حدث نزف واحتقان غالبية الاوردة المركزية وتتخر بعض الخلايا الكبدية وتقجي البعض الآخر منها للكبد عند المعاملة ، عدم انظظام في شكل الوريد المركزي وحدوث احتقان دموي مع وجود تجمعات دهنية. في الحقيقة الدراسات في هذا المجال تكاد

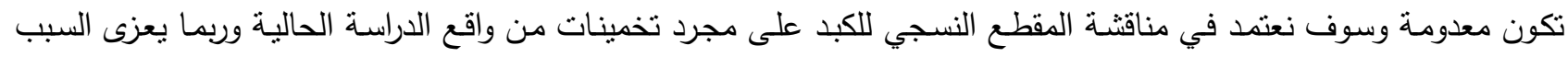
لظهور التأثيرات السلبية للمقاطع النسجية للكبد بالتراكيز العالية لبذور الكتان إلى احتوائه على تركيز عالي من اللكنين والصابونين

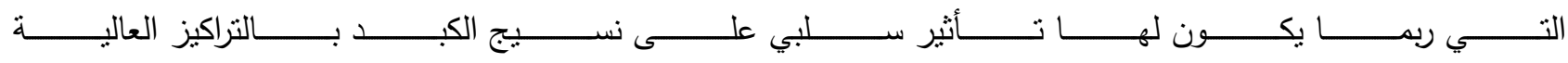

.(Mukherjee et al., 2003)



الثكل 1: صورة نسجية لكبد ذكر طائر السمان لمجموعة السيطرة، يوضح التركيب السوي لنسيج الكبد، يوضح الوريد المركزي

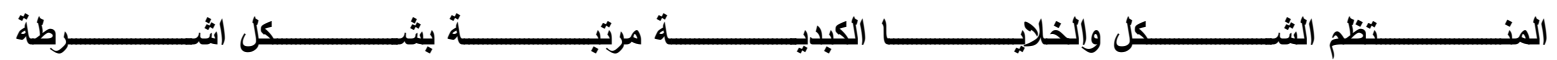

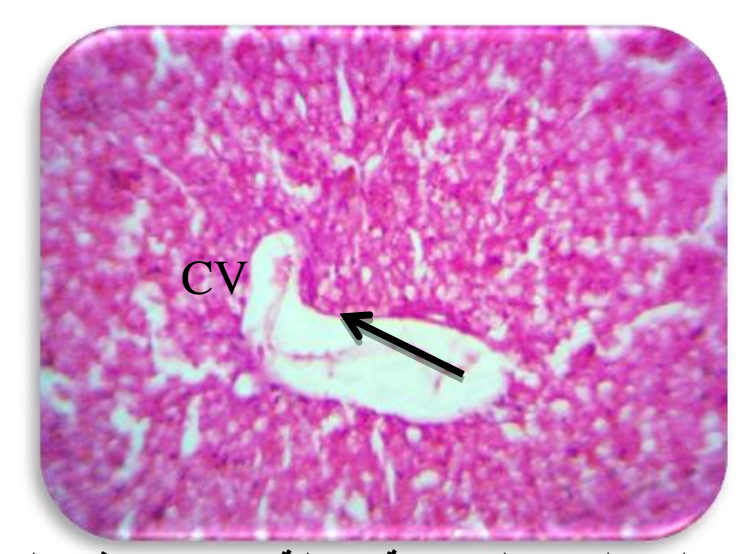

.H\& E400X

الشكل 2: صورة نسجية لكبد ذكر طائر السمان لمجموعة معاملة بمسحوق بذور الكتان بتركيز 250ملفم/كفم وزن جسم يوضح التركيب السوي والثكل المنتظم للوريد المركزي وهو مشابه لمجموعة السبطرة حيث الخلايـا المنتظمـة الثكل 


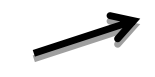

الشكل 3: صورة نسجية لكبد ذكر طائر السمان لمجموعة معاملـة بمسحوق بذور الكتان بتركيز 500ملفم/كفم وزن جسم

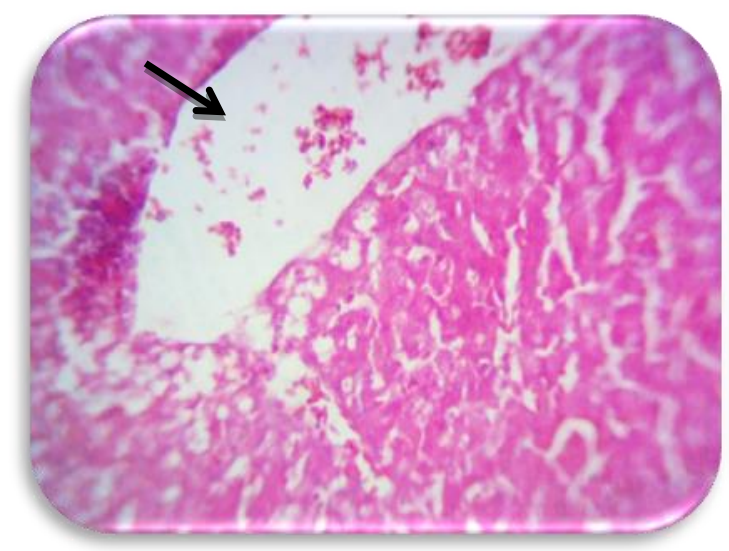

$$
\text { يوضح ظهور تجمعات دهنية وتفجي الخلايا H\& E400X. }
$$

الشكل 4: صورة نسجية لكبد ذكر طائر السمان لمجموعة معاملة بمسحوق بذور الكتان بتركيز 1000ملفم/كفم وزن جسم يوضح

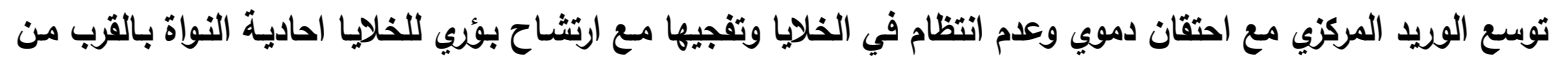
الوريد المركزي H\& E400X.
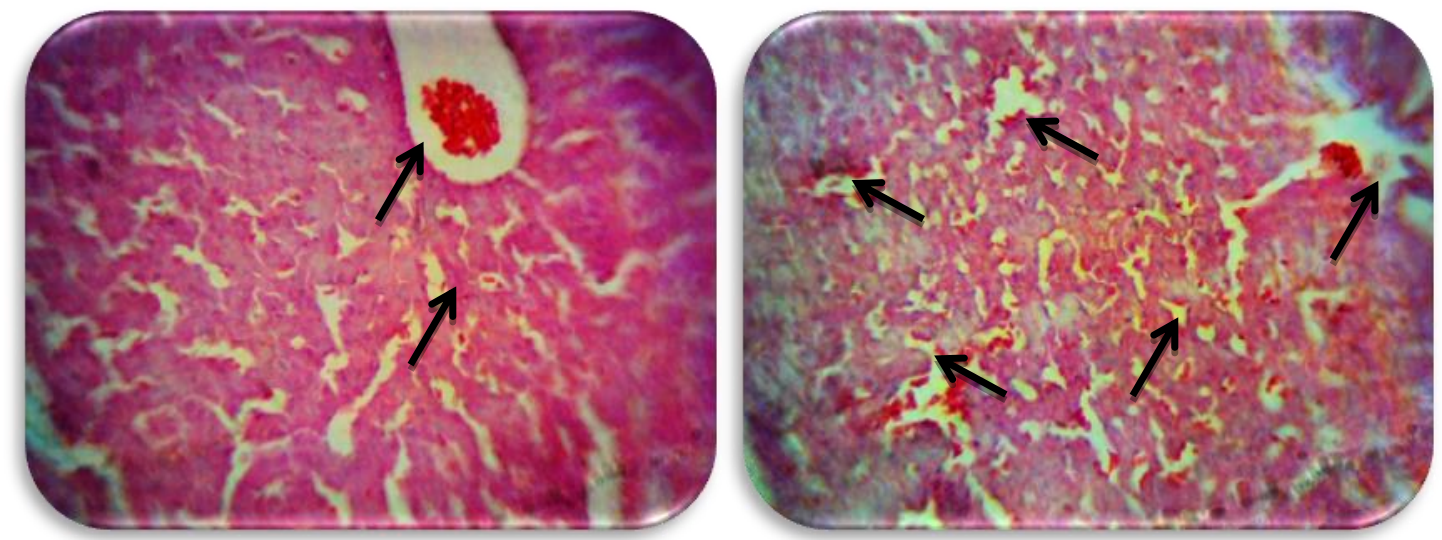

الثكل 5: صورة نسجية لكبد ذكر طائر السمان لمجموعة معاملة بمسحوق بذور الكتان بتركيز 2000ملفم/كفم وزن جسم



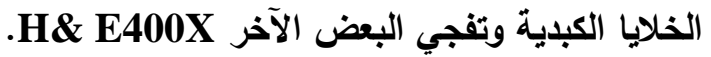




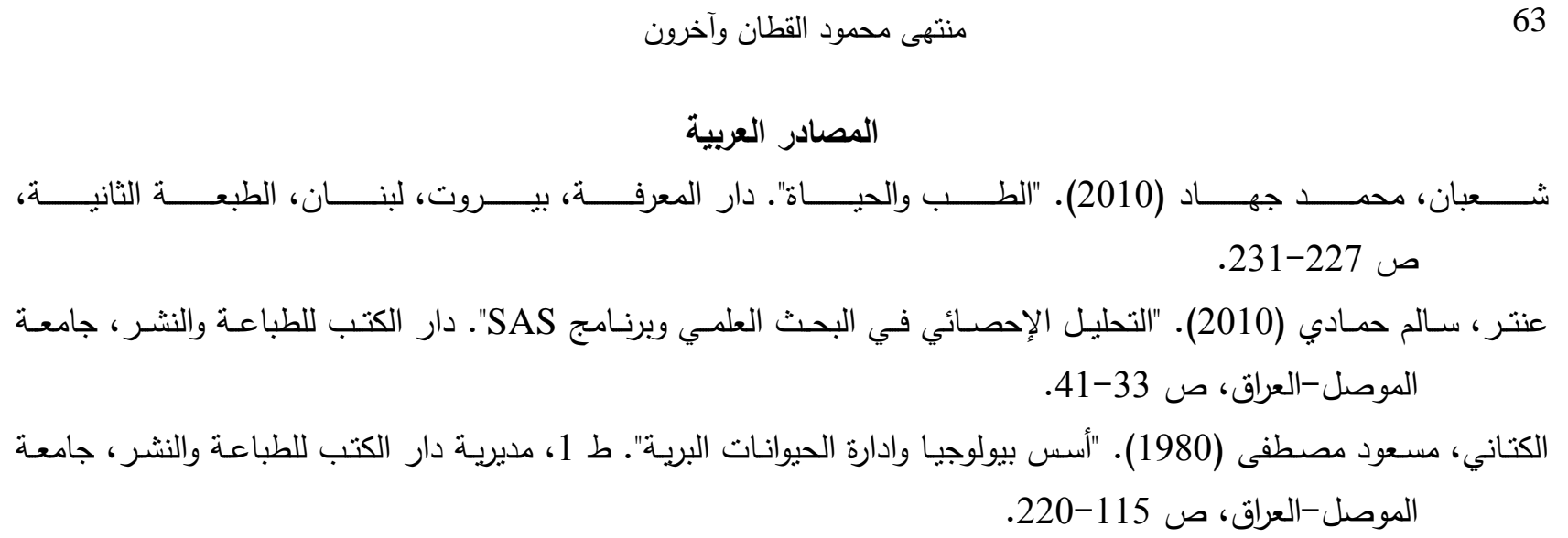

\section{المصادر الأجنبية}

Batchelor, G.R.; Giddins, G. (1995). Body weight changes in laboratory rabbits subjected to transport and different housing conditions. Anim. Technol. (Soussex): The Instilate. Ang., 46(2), 89-95.

Chaudhary, G.D.; Goyall, S.; Priyanka, P. (2010). Hawsonia inermis Linnaeus: A phyto pharmacological. Review and Drug Research. India. 2(2), 91-98.

Cheij, R. (1984). "McDonald Encyclopedia of Medical Plant". McDonald and Co (Publishers), London, pp.206-208.

Devasagayam, T.B.A.; Tilak, J.C.; Boloor, K.K.; Sane, K.S.; Ghaska dbi, S.S.; Lele, R.D. (2004). Free radicals and antioxidant in human heath: Current status and future for spects. Bhabha Atomic Research Centre, Mumbai., JAPI; 52,794-804.

Drury, R.A.B.; Wallgton, E.A.; Cameron, S.R. (1985). "Carleton's Histological Techniques". 4th ed. Oxford Univ. press. New York, pp. 320-355.

Gilbert, H.S.; Stump, D.D.; Reth, E.F. (1984). A method to correct for errors caused by generation of interfering compounds during erythrocyte Lipid peroxidation. Analyt. Biochem., 137, 282-286.

Kind, P.R.N.; King, E.J. (1954). Estimation of phosphatase by determination hydrolysed phenol with amino-antipyrin. J. Clin. Path., 7, 322-326.

Luna, L.G. (1968). "Manual of Histological Staining Methods of the Armed for Armed Forces Institute of Pathology". 33rd edn. The Blackstone Division, MeGraw-Hill Book company, New York, pp.1-45.

Millam, S.; Bohus O.; Anna P. (2005). Plant cell and biotechnology studies in Linum UsitatssimumAveriew. Plant Cell Tissue Organ Calt., 82, 93-103.

Moron, M.S.; Depierre- J.W.; Menney Rik, B. (1979). Levels of glutathione, glutathione reductase and glutathione-s-transfers. Activities in rats lung and liver. Biochem. Biophs. Acta., 582, 67-78.

Morris, H.M. (2007). "Flax: Ahealth and Nutrition prime, Flax council of Canada". Winnipeg, Canada, $140 \mathrm{p}$.

Mukherjee, P. (2003). Plant products with hypocholesterlemic potentials, Adv. Food Nutr. Res., 47, 317-318.

National Research Council. (1994). Nutrient requirement of poultry. Revised national academy press Washington D.C., pp.2-220.

Reitman, S.; Frankel, S. (1957). A Calorimetric method frod the determination of serum glutamic oxaloacetic and pyruric transaminase. Am. J. Clin., 28:56-63.

Setchell, KD. (1998). Phytoestrogens: the biochemistry- physiology and implications for human health of soy isofarones. Am J. Clin. Nutr. 68,13335-13465.1998.

Sreelatha, S.; Inbavalli, R. (2012). Antioxidans, and Antihyperylycemic, and Antihyperlipidemic Effect of corianolrum satirum leaf and Stem in Alloxan- Induced Diabetic Rats. J. Food Science, 11, 20-38.

Tsao, A.S.; Kim, E.S.; Hong, W.K. (2004). Chemoprevention of cancer. J. Clin. 54,150-180.

Wang, L.Q. (2002). Mammalion Phytoestrogens enterodiol and enteroactone. Review. J. Chromatoger, 5(777), 289-309. 